Case Reports
in Dermatology
Case Rep Dermatol 2021;13:42-46

DOI: 10.1159/000511536

Published online: January 25, 2021 (c) 2021 The Author(s)

Published by S. Karger AG, Basel www.karger.com/cde

\title{
Patchy Alopecia in a Patient with Rheumatoid Arthritis: A Practical Application of Trichoscopy
}

\author{
Ahmad Vafaeian Elham Taghizadeh Maryam Daneshpazhooh \\ Hamidreza Mahmoudi \\ Autoimmune Bullous Diseases Research Center, Tehran University of Medical Sciences, \\ Razi Hospital, Tehran, Iran
}

\section{Keywords}

Tinea capitis · Rheumatoid arthritis · Alopecia · Dermoscopy

\section{Abstract}

Trichoscopy is an efficient, convenient, and accurate diagnostic dermatological procedure which is widely used in the examination of patients with skin diseases. Herein, we report a 56year-old woman with a long-term history of rheumatoid arthritis complaining of pruritic patchy alopecia on her scalp who was referred for biopsy to exclude cutaneous lupus erythematosus. Taking advantage of trichoscopy, we were able to quickly diagnose tinea capitis. Following administration of the proper treatment the disease resolved completely.

(C) 2021 The Author(s)

Published by S. Karger AG, Basel

\section{Introduction}

Rheumatoid arthritis (RA) is a chronic autoimmune disease affecting various organs. Although scalp involvement is not common in RA, drug adverse effects and also other concomitant conditions such as hypothyroidism and alopecia areata may result in hair loss in patients with RA [1,2]. Meanwhile, using immunosuppressive agents makes patients with RA prone to 


\section{Case Reports in Dermatology}

Case Rep Dermatol 2021;13:42-46

DOI: $10.1159 / 000511536$

Vafaeian et al.: Trichoscopy for Assessing Alopecia

various infections [3]. Trichoscopy is a noninvasive diagnostic procedure that is increasingly used in dermatological practice while assessing hair disorders [4].

Tinea capitis (TC) is the fungal infection of the scalp skin and hair caused by dermatophytes. If it remains untreated, TC may lead to scarring alopecia and complete hair loss. Due to the protective effects of skin sebum against dermatophytes, TC affects children more frequently than adults. Therefore, scalp dermatophyte infections occur rarely in adults unless patients receive immunosuppressive agents.

Herein, we report a 56-year-old woman affected by RA who presented with multiple alopecic patches on her scalp. Using trichoscopy, we were able to quickly find specific features of dermatophyte infection. Afterward, the infection was confirmed by the $\mathrm{KOH}$ test. The patient was treated with a 6-week course of itraconazole $(100 \mathrm{mg} /$ day) which was followed by a complete improvement of alopecia.

\section{Case Presentation}

A 56-year-old woman with a history of RA for 10 years presented to our outpatient clinic, complaining of patchy hair loss and slight pruritus of the scalp for 3 months. She was referred by the rheumatology service to perform a skin biopsy to exclude cutaneous lupus erythematosus. She was living alone and did not have any pets at her home. The underlying disease had been controlled with oral prednisolone $(10 \mathrm{mg} /$ day $)$ and methotrexate $(12.5 \mathrm{mg} /$ week). On examination, there were several erythematosquamous alopecic patches with a positive pull test on her vertex (Fig. 1). Trichoscopy examination revealed scant scalp scaling alongside comma-shaped, corkscrew, and zigzag hairs, pustules, and also peripilar casts (Fig. 2) [5-7]. According to the trichoscopic findings, TC was considered and a $\mathrm{KOH}$ smear test was performed immediately, which revealed spores and hyphae of dermatophyte inside the hair shafts (Fig. 2). Based on trichoscopy and direct smear findings, the diagnosis of TC was confirmed and the patient was commenced on oral itraconazole $(100 \mathrm{mg} /$ daily) and topical clotrimazole. After 6 weeks of treatment, her symptoms alleviated, alopecia resolved gradually, and the $\mathrm{KOH}$ smear became negative.

\section{Discussion}

In this case report, we introduce a case of recent-onset patchy alopecia in an immunosuppressed patient with RA suspected to have cutaneous lupus erythematosus. By using dermoscopy, we were able to easily detect signs of TC and to rule out skin lupus erythematosus without performing skin biopsy, and thus we were able to treat this patient. In contrast to other rheumatologic disorders such as dermatomyositis and lupus erythematosus, scalp involvement is not a common finding in patients with RA. However, drug adverse effects and concomitant conditions such as hypothyroidism and alopecia areata may cause hair loss in these patients. TC is a fungal infection of the scalp presenting with pruritic and patchy alopecia [8]. In view of its scarring nature, any delay in diagnosis and treatment of TC may lead to cicatricial alopecia. Thus, beginning the appropriate treatment as soon as possible is of high importance for this condition.

As mentioned above, regarding its rarity and different clinical manifestations, TC is not the first suspicion in adult patients with alopecia and normal immune system function [9].

\section{Karger'=}




\section{Case Reports in Dermatology}

Case Rep Dermatol 2021;13:42-46

DOI: $10.1159 / 000511536$

(c) 2021 The Author(s). Published by S. Karger AG, Basel www.karger.com/cde

Vafaeian et al.: Trichoscopy for Assessing Alopecia

Contrary to immunocompetent patients, immunosuppression can pave the way for widespread, atypical, and recurrent fungal infections. Thanks to its simplicity, convenience, and the known diagnostic criteria for TC, trichoscopy can be used as an immediate and accurate diagnostic tool in the dermatological setting. Broken hairs, comma hairs, corkscrew hairs, interrupted hairs (Morse-code hairs), zigzag hairs, scaling, pustules, and crusts are the most common and specific findings in trichoscopy of TC [5-7]. Following suspicion, the KOH test can be used to confirm the diagnosis so the treatment can immediately be instituted. Furthermore, trichoscopy can also be used to predict the treatment response in TC [10].

Altogether, it is crucial for physicians to consider TC as an important differential diagnosis of alopecia in adults. Meanwhile, trichoscopy is a helpful, convenient, and practical diagnostic approach to unveil the disease even as early as the dermatological examination.

\section{Statement of Ethics}

The study was conducted in accordance with the Declaration of Helsinki. Written informed consent was obtained from the patient to publish her case, including images.

\section{Conflict of Interest Statement}

The authors have no conflicts of interest to declare.

\section{Funding Sources}

None.

\section{Author Contributions}

A. Vafaeian: concept; design; definition of intellectual content; literature search; data acquisition; manuscript preparation; manuscript editing; manuscript review/approval. E. Taghizadeh: concept; design; definition of intellectual content; data acquisition; manuscript preparation; manuscript review/approval. M. Daneshpazhooh: design; definition of intellectual content; data acquisition; manuscript preparation; manuscript editing; manuscript review/approval. H. Mahmoudi: concept; definition of intellectual content; literature search; data acquisition; manuscript preparation; manuscript editing; manuscript review/approval.

\section{References}

1 Chu SY, Chen YJ, Tseng WC, Lin MW, Chen TJ, Hwang CY, et al. Comorbidity profiles among patients with alopecia areata: the importance of onset age, a nationwide population-based study. J Am Acad Dermatol. 2011 Nov;65(5):949-56.

2 Anoop J, Geetha F, Jyothi I, Rekha P, Shobha V. Unravelling thyroid dysfunction in rheumatoid arthritis: history matters. Int J Rheum Dis. 2018 Mar;21(3):688-92.

3 Youssef J, Novosad SA, Winthrop KL. Infection risk and safety of corticosteroid use. Rheum Dis Clin North Am. 2016 Feb;42(1):157-76, ix-x.

\section{Karger'=}




\section{Case Reports in Dermatology}

\begin{tabular}{l|l}
\hline Case Rep Dermatol 2021;13:42-46 \\
\hline DOI: 10.1159/000511536 & $\begin{array}{l}\text { (c) 2021 The Author(s). Published by S. Karger AG, Basel } \\
\text { www.karger.com/cde }\end{array}$ \\
\hline
\end{tabular}

Vafaeian et al.: Trichoscopy for Assessing Alopecia

4 Mahmoudi H, Salehi M, Moghadas S, Ghandi N, Teimourpour A, Daneshpazhooh M. Dermoscopic Findings in 126 Patients with Alopecia Areata: A Cross-Sectional Study. Int J Trichology. 2018 May-Jun;10(3):118-23.

5 Pinheiro AM, Lobato LA, Varella TC. Dermoscopy findings in tinea capitis: case report and literature review. An Bras Dermatol. 2012 Mar-Apr;87(2):313-4.

6 El-Taweel AE, El-Esawy F, Abdel-Salam O. Different trichoscopic features of tinea capitis and alopecia areata in pediatric patients. Dermatol Res Pract. 2014;2014:848763.

7 Vastarella M, Gallo L, Cantelli M, Nappa P, Fabbrocini G. An Undetected Case of Tinea Capitis in an Elderly Woman Affected by Dermatomyositis: How Trichoscopy Can Guide to the Right Diagnosis. Skin Appendage Disord. 2019 Apr;5(3):186-8.

8 Al Aboud AM, Crane JS. Tinea Capitis. Treasure Island (FL): StatPearls; 2019.

9 Park SK, Park SW, Yun SK, Kim HU, Park J. Tinea capitis in adults: A 18-year retrospective, single-centre study in Korea. Mycoses. 2019 Jul;62(7):609-16.

10 Richarz NA, Barboza L, Monsonís M, González-Enseñat MA, Vicente A. Trichoscopy helps to predict the time point of clinical cure of tinea capitis. Australas J Dermatol. 2018 Nov;59(4):e298-9.

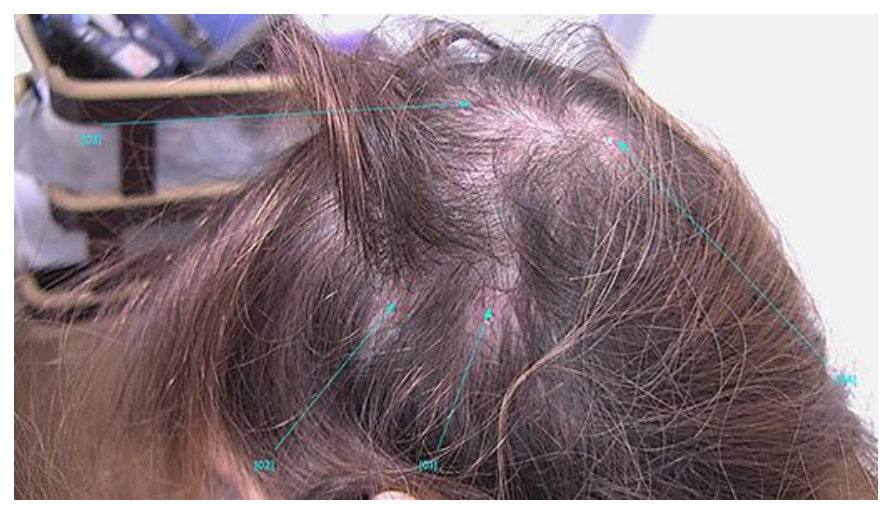

Fig. 1. Multiple erythematosquamous alopecic patches on the scalp of a 56-year-old woman. 


\section{Case Reports in Dermatology}

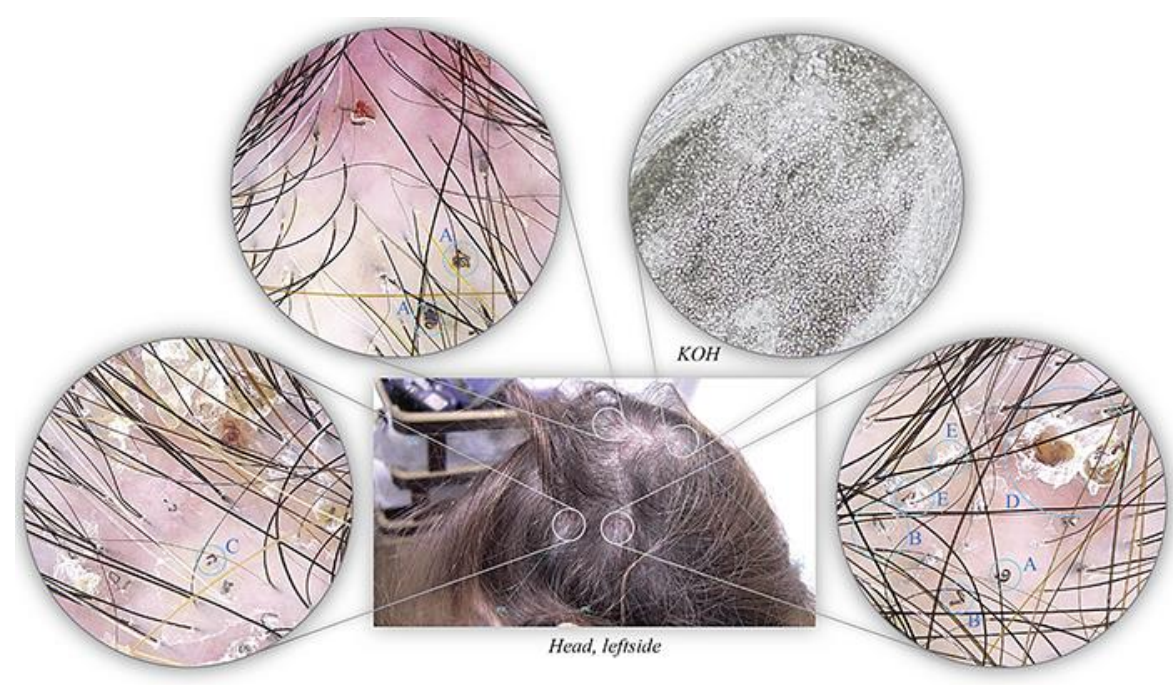

Fig. 2. Trichoscopic examination $(20 \times)$ and $\mathrm{KOH}$ test $(400 \times)$ results of alopecic patches: A, corkscrew hairs; B, zigzag hairs; C, comma hairs; D, pustule; E, perifollicular scaling. KOH examination revealed multiple hyphae and spores inside the hair shafts known as endothrix. Dermoscopic images were captured by FotoFinder Medicam 1000 (FotoFinder Systems GmbH, Bad Birnbach, Germany). 